\title{
Predictors of Hospital Readmission within 30 Days after Coronary Artery Bypass Grafting: Data Analysis of 2,272 Brazilian Patients
}

Camilla do Rosário Nicolino Chiorino 1,2 RN, MSc; Vinicius Batista Santos³, RN, MSc, PhD; Juliana de Lima Lopes ${ }^{3}, \mathrm{RN}$, MSc, PhD; Camila Takao Lopes ${ }^{2,3}$, RN, MSc, PhD, FNI

DOI: $10.21470 / 1678-9741-2020-0266$

\begin{abstract}
Introduction: In order to reduce readmission rates after coronary artery bypass grafting (CABG), its predictors should be known in different contexts. The objective of this study was to identify predictive factors of hospital readmission within $\mathbf{3 0}$ days after CABG in a Brazilian center.

Methods: A secondary analysis of an electronic database of patients submitted to isolated CABG was performed. The relationship between readmission within 30 days and demographic, anthropometric, clinical, and surgery-related characteristics was investigated by univariate analyses. Predictors were identified by multiple logistic regression.

Results: Data from 2,272 patients were included, with an incidence of readmission of $8.6 \%$. The predictors of readmission
\end{abstract}

were brown skin color (Beta $=1.613 ; 95 \%$ confidence interval $[\mathrm{Cl}]$ 1.047-2.458; $P=0.030$ ), African-American ethnicity (Beta $=0.136$; 95\% Cl 0.019-0.988; $P=0.049$ ), chronic kidney disease (Beta=2.214; $95 \% \mathrm{Cl} 1.269-3.865 ; P=0.005)$, postoperative use of blood products (Beta=1.515; 95\% Cl 1.101-2.086; $P=0.011$ ), chronic obstructive pulmonary disease (Beta=2.095; 95\% Cl 1.284-3.419; $P=0.003)$, and use of acetylsalicylic acid (Beta=1.418; $95 \% \mathrm{Cl} 1.000-2.011 ; P=0.05$ ). Preoperative antibiotic prophylaxis (Beta $=0.742 ; 95 \% \mathrm{Cl}$ 0.5471.007; $P=0.055$ ) was marginally significant.

Conclusion: The predictors identified may support a closer postoperative follow-up and individualized planning for a safe discharge.

Keywords: Myocardial Revascularization. Risk Factors. Patient Readmission. Postoperative Period.

\section{Abbreviations, acronyms \& symbols}

\begin{tabular}{ll}
\hline ARB & $=$ Angiotensin II receptor blocker \\
ASA & $=$ Acetylsalicylic acid \\
BMI & $=$ Body mass index \\
CABG & $=$ Coronary artery bypass grafting \\
CAD & $=$ Coronary artery disease \\
CI & $=$ Confidence interval \\
CKD & $=$ Chronic kidney disease \\
COPD & $=$ Chronic obstructive pulmonary disease \\
DM & $=$ Diabetes mellitus \\
EuroSCORE & $=$ European System for Cardiac Operative Risk Evaluation \\
HF & $=$ Heart failure \\
IABP & $=$ Intra-aortic balloon pump \\
MI & $=$ Myocardial infarction \\
REVASC & $=$ Registro de Revascularização Miocárdica \\
USA & $=$ United States of America
\end{tabular}

'Educação Corporativa da Associação Beneficência Portuguesa de São Paulo, São Paulo, Brazil.

${ }^{2}$ Programa de Pós-Graduação em Enfermagem, Escola Paulista de Enfermagem, Universidade Federal de São Paulo, São Paulo, Brazil.

2Departamento de Enfermagem Clínica e Cirúrgica, Escola Paulista de Enfermagem, Universidade Federal de São Paulo, São Paulo, Brazil.

\section{INTRODUCTION}

Coronary artery bypass grafting (CABG) is the most common cardiovascular procedure in the world. In the United States of America (USA), 160,160 CABG were performed in 2017 [1]. From August 2014 to December 2016, 54.1\% of cardiac surgeries performed in Brazil were CABG $^{[2]}$. In 2013, the mean rate of CABG in the countries of the Organization for Economic Co-operation and Development was 44 per 100,000 inhabitants ${ }^{[3]}$, whereas in Brazil, between 2000 and 2017, the gross rate of CABG financed by the Brazilian Unified Health System ranged between 15.1 and 18.3 per 100,000 inhabitants aged 20 years or more ${ }^{[4]}$.

After $C A B G$, hospital readmission within 30 days ranges between $6.1 \%$ and $23.6 \%$ in countries such as the USA, Canada, Lebanon, and Turkey ${ }^{[5-15]}$. The causes of readmission include infection, pulmonary complications, myocardial infarction (MI), arrhythmias, and others ${ }^{[6,9-11,15]}$. Out of 288,059 patients submitted to CABG in the USA between 2013 and 2014, the

Correspondence Address:

Camila Takao Lopes

(iD) https://orcid.org/0000-0002-6243-6497

Escola Paulista de Enfermagem, Universidade Federal de São Paulo (EPE-UNIFESP)

Rua Napoleão de Barros, 754, São Paulo, SP, Brazil - Zip Code: 04024-002

E-mail: ctlopes@unifesp.br 
average cost per readmission within 30 days was approximately US\$13,500, with a mortality rate of $2.3 \%$. Therefore, reducing readmission after $C A B G$ is a priority ${ }^{[16]}$.

Several studies have investigated the predictors of readmission within 30 days following CABG. Patient-related predictors include demographic data (e.g., age and gender), anthropometric data (e.g., weight), and clinical aspects (e.g., number of comorbidities). Surgery-related predictors include, e.g., surgical urgency, number of bypasses, and length of hospital stay ${ }^{[5-15]}$. However, to the best of our knowledge, in Brazil there are no robust studies that investigated predictors of readmission after $C A B G$, in order to support multiprofessional interventions to minimize these rates.

This study aimed to identify predictive factors of hospital readmission within 30 days after CABG in a Brazilian center.

\section{METHODS}

A secondary analysis of an electronic database was conducted in the largest private health center in Latin America, which has 1,084 beds and performs around 330 cardiac surgeries monthly. The hospital is located in the city of São Paulo (São Paulo, Brazil).

The sample was composed of data from the Registro de Revascularização Miocárdica (REVASC) electronic database, which contains 243 variables of 3,010 patients submitted to CABG by the 14 cardiac surgery teams of the institution, representing $69.6 \%$ of the total surgeries performed between July 2009 and July 2010.

The inclusion criteria were as follows: patients older than 18 years, submitted to isolated CABG, who had been discharged alive, and with a hospital length of stay of up to 10 days. Patients with unavailable data on risk factors and outcomes at the REVASC database were excluded.

The antecedent variables were selected from those available in the REVASC database and based on the results of 10 studies that investigated the predictors of hospital readmission within 30 days following CABG through multivariate analyses, published from 2013 to $2018^{[5,7-15]}$.

\section{Patient-Related Variables}

Patient-related variables were gender (male/female), age (in years), ethnicity as stated by the patient himself (Caucasian/ African-American/Mixed [African-American and Caucasian]/ Asian/Other), anthropometric characteristics (body mass index $[\mathrm{BMI}]\left[\mathrm{Kg} / \mathrm{m}^{2}\right]$ ), use of medicines (oral anticoagulants, acetylsalicylic acid [ASA], ticlopidine, clopidogrel, antiplatelet agents, beta-blockers, cardiac glycosides, oral nitrates, intravenous nitrate, calcium channel blocker, angiotensinconverting enzyme inhibitors, angiotensin II receptor blocker [ARB], intravenous inotrope and/or statins), life habits smoking (never smoked, past smoker [ $>1$ month], smoker $[<1$ month]) —, family history of coronary artery disease (CAD) angina, $\mathrm{MI}$, or CAD when less than 55 years old in first-degree relatives -, diabetes mellitus (DM), DM treatment (none, diet, oral medications, insulin), dyslipidemia, chronic kidney disease (CKD), dialysis, hypertension, previous stroke, chronic obstructive pulmonary disease (COPD), peripheral artery disease, cerebrovascular disease, previous angioplasty/stent, previous MI, time since previous MI (<6 hours, 6-24 hours, 1-7 days, 8-21 days, $>21$ days), heart failure (HF), angina, angina classification (stable/ unstable), arrhythmia, cardiac catheterization, vessel disease (> 70\%) (none/one/two/three), left coronary trunk injury (> 50\%), injury in the proximal anterior descending coronary artery $>$ 70\%, mortality as estimated by the European System for Cardiac Operative Risk Evaluation (EuroSCORE) ${ }^{[17]}$, and use of intra-aortic balloon pump (IABP).

\section{Surgery-Related Variables}

Surgery-related variables were use of preoperative antibiotic prophylaxis, surgery indication (elective/urgency/emergency), use of intraoperative antibiotic prophylaxis, number of anastomoses with venous conduits, number of anastomoses with arterial conduits (use of the internal thoracic artery [none/right/left/both]), number of anastomoses with distal arterial conduits, use of radial artery, use of the gastroepiploic artery, coronary endarterectomy (none/right coronary/anterior descendent/diagonal/circumflex/ marginal), extracorporeal circulatory support, degree of hypothermia $\left(28^{\circ} \mathrm{C} / 31^{\circ} \mathrm{C} / 34^{\circ} \mathrm{C} /\right.$ normothermia), duration of aortic cross-clamping, and duration of perfusion.

Postoperative aspects were blood product transfusion, need for orotracheal reintubation during hospital stay, antibiotic suspension within 48 hours of surgery, use of ASA, intravenous insulin in the first 24 postoperative hours, prophylaxis for deep venous thrombosis, thrombocytopenia (until discharge), serum creatinine, and length of hospital stay.

The outcome variable was 30-day all-cause hospital readmission after isolated CABG. The time between surgery and readmission was calculated as the date of readmission minus the date of surgery. When more than one readmission occurred in 30 days, the first documented readmission was considered.

The variables were described according to mean, standard deviation, quartiles, and minimum and maximum values for quantitative variables. As to qualitative variables, absolute and relative frequencies were used. The confidence intervals were calculated when appropriate.

The relationship between the outcome and the clinical and demographic variables was investigated by Student's $t$-test for quantitative variables or by Chi-square (or Fisher's exact) test for the qualitative variables. The relationship of the outcome with the variables with a $P$-value $\leq 0.2$ in the univariate tests was investigated by a multiple logistic regression model. A significance of 0.05 was considered and, for the analyses, IBM SPSS Statistics for Windows, Version 25.0, Armonk, NY: IBM Corp. and $\mathrm{R}$ software were used.

This research project was approved by the Research Ethics Committee of the University (Protocol No. 2.795.813) and of the hospital where the study was conducted (Protocol No. 2.933.217). Confidentiality and anonymity of patient data were maintained.

\section{RESULTS}

Among the 3,010 patients at REVASC database, 2,272 patients were older than 18 years, had undergone isolated $C A B G$, and were discharged alive within 10 days after surgery. Of 
these patients, the most prevalent were male, Caucasian, with a mean age of $62.2 \pm 9.77$ years, and BMI $27.39 \pm 4.23$ (Table 1). The most common comorbidities in our sample were hypertension, dyslipidemia, and angina. Most patients used ASA and oral nitrates (Table 1).

A total of 195 (8.6\%) patients were readmitted within 30 days of CABG, of which 123 (63.1\%) were readmitted for non- cardiovascular causes and 36.9\% for cardiovascular causes. The main causes of readmission were surgical wound infection (20.51\%), HF (13.85\%), and pneumonia (10.26\%) (Table 2).

In the univariate analysis, the characteristics that were associated with readmission with a $P$-value $\leq 0.20$ were age $(P=160)$, ethnicity $(P=0,016), D M$ treatment $(P=0.196), C K D$ $(P=0.002)$, dialysis $(P=0.041)$, hypertension $(P=0.062)$, COPD

Table 1. Main demographic and clinical characteristics ( $n=2272)$.

\begin{tabular}{|c|c|c|c|}
\hline & & $\mathbf{n}$ & $\%$ \\
\hline \multicolumn{2}{|l|}{ Male gender } & 1616 & 71.13 \\
\hline \multirow{4}{*}{ Ethnicity } & Caucasian & 1926 & 84.77 \\
\hline & African-American & 86 & 3.79 \\
\hline & Mixed (Caucasian and African-American) & 228 & 10.04 \\
\hline & Asian & 32 & 1.41 \\
\hline \multirow{2}{*}{ Comorbidities } & Family history of coronary artery disease & 703 & 30.94 \\
\hline & Diabetes & 809 & 35.61 \\
\hline \multirow{4}{*}{ Diabetes mellitus treatment } & None & 52 & 2.29 \\
\hline & Diet & 21 & 0.92 \\
\hline & Oral & 489 & 21.52 \\
\hline & Insulin & 247 & 10.87 \\
\hline \multicolumn{2}{|l|}{ Dyslipidemia } & 1011 & 44.50 \\
\hline \multicolumn{2}{|l|}{ Chronic kidney disease } & 98 & 4.31 \\
\hline \multicolumn{2}{|l|}{ Hemodialysis } & 20 & 0.88 \\
\hline \multicolumn{2}{|l|}{ Hypertension } & 1870 & 82.31 \\
\hline \multicolumn{2}{|l|}{ Stroke } & 104 & 4.58 \\
\hline \multicolumn{2}{|l|}{ Chronic obstructive pulmonary disease } & 137 & 6.03 \\
\hline \multicolumn{2}{|l|}{ Peripheral arterial disease } & 89 & 3.92 \\
\hline \multicolumn{2}{|l|}{ Cerebrovascular disease } & 35 & 1.54 \\
\hline \multicolumn{2}{|l|}{ Heart failure } & 39 & 1.72 \\
\hline \multicolumn{2}{|l|}{ Angina } & 1717 & 75.57 \\
\hline \multirow{2}{*}{ Angina classification } & Stable & 1323 & 58.23 \\
\hline & Unstable & 394 & 17.34 \\
\hline \multicolumn{2}{|l|}{ Angioplasty/previous stent } & 217 & 9.55 \\
\hline \multicolumn{2}{|l|}{ Previous myocardial infarction } & 1060 & 46.65 \\
\hline \multirow{6}{*}{ Time since previous myocardial infarction } & $<6$ hours & 22 & 0.97 \\
\hline & 6-24 hours & 3 & 0.13 \\
\hline & 1-7 days & 27 & 1.19 \\
\hline & 8-21 days & 128 & 5.63 \\
\hline & $>21$ days & 880 & 38.73 \\
\hline & Arrhythmia & 100 & 4.40 \\
\hline
\end{tabular}




\begin{tabular}{|c|c|c|c|}
\hline \multirow{3}{*}{ Smoking } & Never smoked & 1008 & 44.37 \\
\hline & Past smoker (> 1 month) & 901 & 39.66 \\
\hline & Smoker (> 1 month) & 363 & 15.98 \\
\hline \multirow{14}{*}{ Medication } & Oral anticoagulation & 12 & 0.53 \\
\hline & Acetylsalicylic acid & 1592 & 70.07 \\
\hline & Ticlopidine & 25 & 1.10 \\
\hline & Clopidogrel & 249 & 10.96 \\
\hline & Antiplatelet agents & 124 & 5.46 \\
\hline & Beta-blockers & 1472 & 64.79 \\
\hline & Cardiac glycosides & 32 & 1.41 \\
\hline & Oral nitrates & 1417 & 62.37 \\
\hline & Intravenous nitrates & 71 & 3.13 \\
\hline & Calcium channel blocker & 417 & 18.35 \\
\hline & Angiotensin-converting enzyme inhibitors & 1088 & 47.89 \\
\hline & Angiotensin II receptor blocker & 394 & 17.34 \\
\hline & Intravenous inotropic agents & 2 & 0.09 \\
\hline & Statin & 1537 & 67.65 \\
\hline
\end{tabular}

( $P=0.001)$, previous angioplasty/stent $(P=0.171)$, time since previous MI $(P=0.124)$, use of ASA ( $P=0.029)$, use of antiplatelet agents $(P=0.126)$, use of ARB ( $P=0.069)$, mortality expected by EuroSCORE ( $P=0.015)$, preoperative prophylaxis $(P=0.052)$, cardiac catheterization $(P=0.098)$, duration of aortic cross-clamping ( $P=0.193)$, need for orotracheal reintubation $(P=0.094)$, intensive care unit readmission $(P=0.156)$, and postoperative transfusion of blood products $(P=0.004)$.

In the logistic regression, the variables that remained significantly related to readmission were mixed ethnicity, AfricanAmerican ethnicity, CKD, COPD, use of ASA, and postoperative transfusion of blood products. Preoperative antibiotic prophylaxis was marginally significant (Table 3).

\section{DISCUSSION}

This study identified predictors of hospital readmission within 30 days of isolated CABG in a large cohort of 2,272 Brazilian patients. To the best of our knowledge, this is the first study that identified these factors in a large sample in Brazil. Although our results are limited by the inclusion of data from patients submitted to CABG in a single center, we believe the results can be generalizable, given that the demographic and clinical characteristics of our sample, as well as the $8.6 \%$ prevalence of readmission, is similar to that found in previous studies ${ }^{[1,5-18]}$.

Although the relationship between preoperative antibiotic prophylaxis and readmission was marginally significant, this relationship is clinically significant, considering that surgical wound infection was the main cause for readmission. In our sample, all patients underwent pre- or intraoperative antibiotic prophylaxis. However, only $60 \%$ of the patients received the antibiotic one hour before the incision and only $87.2 \%$ had the antibiotic repeated after four hours (data not shown), as indicated by the Centers for Disease Control and Prevention ${ }^{[16]}$ for prevention of surgical wound infection. Similar to our results, the most recent study based on the New York State Registry found that the main causes of readmission after CABG were infection (16.9\%) and HF (12.8\%) ${ }^{[19]}$. Other studies support surgical wound infection, HF, and pneumonia as frequent causes of readmission $^{[6,9,11,15] \text {. }}$.

Previous studies found a 16-74\% higher chance of readmission in African-American patients ${ }^{[8,9,14]}$. In our sample, although mixed ethnicity was associated with a $61 \%$ higher chance of readmission, the African-American ethnicity was associated with an $86 \%$ lower chance of readmission, which can be explained by the inexpressive representativeness of patients who self-declared as African-American in our sample (3.8\%), with only one patient being readmitted after the surgery.

In our sample, CKD increased the chance of readmission up to 2.21 times. Previous studies found that $C K D^{[15,17]}$ and creatinine levels predict early readmission after CABG in a severitydependent manner: the increased chances of readmission ranged between $27 \%$ and twofold, depending on the creatinine level and need for dialysis ${ }^{[5]}$.

Similarly, the literature shows that not only COPD, but its severity, was an important determinant of increased chance of readmission after $C A B G^{[5,12,15]}$, ranging from $10 \%$ in mild COPD to $58 \%$ in severe COPD. In our study, having COPD increased the chance of readmission by more than twofold.

Although COPD compensation measures are wellestablished during preoperative clinical assessment to determine the indication of $\mathrm{CABG}^{[19]}$ and even though it is not possible to 
Table 2. Causes of readmission within 30 days after coronary artery bypass grafting $(n=195)$.

\begin{tabular}{l|c|c}
\hline Type of Complication & $\mathbf{n}$ & $\%$ \\
\hline Cardiovascular & 72 & 36.92 \\
\hline Hypertensive peak & 1 & 0.51 \\
\hline Angina & 6 & 3.08 \\
\hline Stroke & 6 & 3.08 \\
\hline Pulmonary thromboembolism & 6 & 3.08 \\
\hline Arrhythmia & 7 & 3.59 \\
\hline Myocardial infarction & 7 & 3.59 \\
\hline Others & 12 & 6.15 \\
\hline Heart failure & 27 & 13.85 \\
\hline Non-cardiovascular & 123 & 63.08 \\
\hline Deep wound infection not requiring & 9 & 4.62 \\
\hline reoperation & 15 & 7.69 \\
\hline Deep wound infection requiring reoperation & 20 & 10.26 \\
\hline Pneumonia & 38 & 19.49 \\
\hline Others & 40 & 20.51 \\
\hline Superficial wound infection & & \\
\hline
\end{tabular}

Table 3. Logistic regression for readmission within 30 days after coronary artery bypass grafting $(n=2272)$.

\begin{tabular}{|c|c|c|c|c|}
\hline Variable & $P$-value & Beta & $95 \% \mathrm{Cl}$ & \\
\hline & & & Inferior & Superior \\
\hline African-American/Caucasian & 0.049 & 0.136 & 0.019 & 0.988 \\
\hline Mixed/Caucasian & 0.030 & 1.613 & 1.047 & 2.458 \\
\hline Chronic kidney disease & 0.005 & 2.214 & 1.269 & 3.865 \\
\hline Chronic obstructive pulmonary disease & 0.003 & 2.095 & 1.284 & 3.419 \\
\hline Acetylsalicylic acid & 0.050 & 1.418 & 1.000 & 2.011 \\
\hline Transfusion of blood products & 0.011 & 1.515 & 1.101 & 2.086 \\
\hline Preoperative antibiotic prophylaxis & 0.055 & 0.742 & 0.547 & 1.007 \\
\hline
\end{tabular}

$\mathrm{Cl}=$ confidence interval

fully reverse airflow limitation in this kind of patients, rigorous preoperative screening using the results of six-minute walking test, pulmonary and cardiac rehabilitation, and interventions for adherence to inhaled medication can assist on reducing morbimortality in these patients. Such interventions require further studies with COPD patients ${ }^{[5,20,21]}$.

Previous meta-analyses including 2,399 patients show that the preoperative use of ASA is associated with a reduction in the risk of postoperative $\mathrm{Ml}$, without reducing mortality, but it also increases the risk of chest bleeding/drainage, the need for packed red blood cell transfusion, and bleeding-related reoperation after $\mathrm{CABG}^{[22]}$. Therefore, another variable that should be readily known upon admission is the use of ASA, which was associated with a $41 \%$ greater chance of readmission in our sample.

A previous study found that the need for transfusion of blood products by $25.1 \%$ of patients undergoing CABG was associated with a $76 \%$ greater chance of hospital readmission ${ }^{[12]}$. In our study, over 59\% received blood components, which impacted on a 1.5-fold greater chance of readmission for these patients. In fact, patients with severe bleeding who are transfused two 
units of packed red blood cell after CABG have increased risk of adverse events that increase patient severity, such as acute kidney injury and surgical wound infection, prolonged use of inotropic drugs, and IABP $[23,24]$.

The predictors ethnicity, CKD, COPD, and use of ASA are variables easily obtained through patient reporting, which enacts prediction of the risk as soon as the patient is admitted, as well as the planning of postoperative follow-up. Transfusion of blood components complements the group of predictors that should be postoperatively evaluated, thereby signaling the need for closer monitoring.

By considering the predictors found in this study, cardiac programs to decrease the risk of readmission after CABG must be implemented, including several professionals, such as nurses, psychologists, and physiotherapists. These programs must be performed in all institutions to evaluate the patients before the surgery and prepare them and their families after the surgery to change modifiable risk factors and improve medication adherence and cardiac rehabilitation.

\section{Limitations}

The main limitation of the study is related to the retrospective analysis of the database regarding to the full data collection and completeness of the outcomes.

\section{CONCLUSION}

The predictors associated with a greater chance of hospital readmission within 30 days after isolated CABG were mixed ethnicity, use of ASA, transfusion of blood components, CKD, and COPD. The African-American ethnicity was associated with a lower chance of readmission. The association between preoperative antibiotic prophylaxis and a lower chance of readmission was marginally significant. Our data indicate that these patients require closer postoperative follow-up.

\section{REFERENCES}

1. D'Agostino RS, Jacobs JP, BadhwarV, Fernandez FG, Paone G, Wormuth DW, et al. The society of thoracic surgeons adult cardiac surgery database: 2019 update on outcomes and quality. Ann Thorac Surg. 2019;107(1):24-32. doi:10.1016/j.athoracsur.2018.10.004.

2. Gomes WJ, Moreira RS, Zilli AC, Bettiati LC Jr, Figueira FAMDS, D' Azevedo SSP, et al. The Brazilian registry of adult patient undergoing cardiovascular surgery, the BYPASS project: results of the first 1,722 patients. Braz J Cardiovasc Surg. 2017;32(2):71-6. Erratum in: Braz J Cardiovasc Surg. 2017t;32(5):442. doi:10.21470/1678-9741-2017-0053.

3. Head SJ, Milojevic M, Taggart DP, Puskas JD. Current practice of state-of-the-art surgical coronary revascularization. Circulation. 2017;136(14):1331-45. doi:10.1161/CIRCULATIONAHA.116.022572.

4. PROADESS - Avaliação do Desempenho do Sistema de Saúde [Internet]. Rio de Janeiro: Laboratório de Informação em Saúde; ICICT; Fiocruz [cited 2020 Sept. 30]. Available from: https://www.proadess.icict.fiocruz.br/ index.php?pag=fic\&cod=A13\&tab=1.

5. Shahian DM, He X, O'Brien SM, Grover FL, Jacobs JP, Edwards FH, et al. Development of a clinical registry-based 30-day readmission measure

\section{ACKNOWLEDGMENTS}

To the Research group, represented by Flavia Cortez Colosimo, Gilmara Silveira da Silva, and Alexandre Gonçalves Sousa, of the Education and Research Group at Beneficência Portuguesa, for their work on the REVASC database, and to the statistician Luiza Laureano Gonçalves, for the consultancy.

\section{No financial support.}

No conflict of interest.

\section{Authors' roles \& responsibilities}

CRNC Substantial contributions to the conception of the work; analysis and interpretation of data for the work; drafting the work; agreement to be accountable for all aspects of the work in ensuring that questions related to the accuracy or integrity of any part of the work are appropriately investigated and resolved; final approval of the version to be published

VBS Interpretation of data for the work; revising the work critically for important intellectual content; final approval of the version to be published

JLL Interpretation of data for the work; revising the work critically for important intellectual content; final approval of the version to be published

CTL Substantial contributions to the conception of the work; analysis and interpretation of data for the work; revising the work critically for important intellectual content; agreement to be accountable for all aspects of the work in ensuring that questions related to the accuracy or integrity of any part of the work are appropriately investigated and resolved; final approval of the version to be published for coronary artery bypass grafting surgery. Circulation. 2014;130(5):399409. doi:10.1161/CIRCULATIONAHA.113.007541.

6. Shehata N, Forster A, Li L, Rothwell DM, Mazer CD, Naglie G, et al. Does anemia impact hospital readmissions after coronary artery bypass surgery? Transfusion. 2013;53(8):1688-97; quiz 1687. doi:10.1111/ trf.12007.

7. Shah RM, Zhang Q, Chatterjee S, Cheema F, Loor G, Lemaire SA, et al. Incidence, cost, and risk factors for readmission after coronary artery bypass grafting. Ann Thorac Surg. 2019;107(6):1782-9. doi:10.1016/j. athoracsur.2018.10.077.

8. Li Y, Cai X, Mukamel DB, Cram P. Impact of length of stay after coronary bypass surgery on short-term readmission rate: an instrumental variable analysis. Med Care. 2013;51(1):45-51. doi:10.1097/ MLR.0b013e318270bc13.

9. Benuzillo J, Caine W, Evans RS, Roberts C, Lappe D, Doty J. Predicting readmission risk shortly after admission for CABG surgery. J Card Surg. 2018;33(4):163-70. doi:10.1111/jocs.13565.

10. Fanari Z, Elliott D, Russo CA, Kolm P, Weintraub WS. Predicting 
readmission risk following coronary artery bypass surgery at the time of admission. Cardiovasc Revasc Med. 2017;18(2):95-9. doi:10.1016/j. carrev.2016.10.012.

11. Saab S, Noureddine S, Dumit NY. Readmission rates and emergency department visits after coronary artery bypass graft surgery and related factors. J Med Liban. 2013;61(3):155-60. doi:10.12816/0001444.

12. Lancey R, Kurlansky P, Argenziano M, Coady M, Dunton R, Greelish J, et al. Uniform standards do not apply to readmission following coronary artery bypass surgery: a multi-institutional study. J Thorac Cardiovasc Surg. 2015;149(3):850-7.e1; discussion 857. doi:10.1016/j. jtcvs.2014.08.059.

13. Engoren M, Schwann TA, Habib RH. Elevated hemoglobin A1C is associated with readmission but not complications. Asian Cardiovasc Thorac Ann. 2014;22(7):800-6. doi:10.1177/0218492313515895.

14. Zywot A, Lau CSM, Glass N, Bonne S, Hwang F, Goodman K, et al. Preoperative scale to determine all-cause readmission after coronary artery bypass operations. Ann Thorac Surg. 2018;105(4):1086-93. doi:10.1016/j.athoracsur.2017.11.062.

15. Feng TR, White RS, Gaber-Baylis LK, Turnbull ZA, Rong LQ. Coronary artery bypass graft readmission rates and risk factors - a retrospective cohort study. Int J Surg. 2018;54(Pt A):7-17. doi:10.1016/j.ijsu.2018.04.022.

16. Roques F, Nashef SA, Michel P, Gauducheau E, de Vincentiis C, Baudet

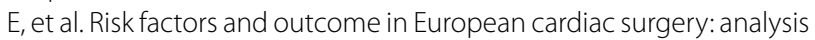
of the EuroSCORE multinational database of 19030 patients. Eur J Cardiothorac Surg. 1999;15(6):816-22; discussion 822-3. doi:10.1016/ s1010-7940(99)00106-2.

17. Shahian DM, O'Brien SM, Sheng S, Grover FL, Mayer JE, Jacobs JP, et al. Predictors of long-term survival after coronary artery bypass grafting surgery: results from the society of thoracic surgeons adult cardiac surgery database (the ASCERT study). Circulation. 2012;125(12):1491500. doi:10.1161/CIRCULATIONAHA.111.066902.

18. Parhar K, Zochios V. Outcomes of patients with COPD undergoing cardiac surgery: don't hold your breath. J Cardiothorac Vasc Anesth. 2018;32(5):2246-7. doi:10.1053/j.jvca.2018.02.004.

19. Velazquez EJ, Lee KL, Jones RH, Al-Khalidi HR, Hill JA, Panza JA, et al. Coronary-artery bypass surgery in patients with ischemic cardiomyopathy. N Engl J Med. 2016;374(16):1511-20. doi:10.1056/ NEJMoa1602001.

20. Hastings S, Myles P, Mcllroy D. Aspirin and coronary artery surgery: a systematic review and meta-analysis. Br J Anaesth. 2015;115(3):376-85. doi:10.1093/bja/aev164.

21. Kinnunen EM, De Feo M, Reichart D, Tauriainen T, Gatti G, Onorati F, et al. Incidence and prognostic impact of bleeding and transfusion after coronary surgery in low-risk patients. Transfusion. 2017;57(1):178-86. doi:10.1111/trf.13885.

22. Liu W, Xi Z, Gu C, Dong R, AlHelal J, Yan Z. Impact of major bleeding on the risk of acute kidney injury in patients undergoing off-pump coronary artery bypass grafting. J Thorac Dis. 2018;10(6):3381-9. doi:10.21037/ jtd.2018.05.98.

23. Kinnunen EM, Zanobini M, Onorati F, Brascia D, Mariscalco G, Franzese I, et al. The impact of minor blood transfusion on the outcome after coronary artery bypass grafting. J Crit Care. 2017;40:207-12. doi:10.1016/j. jcrc.2017.04.025.

24. Mary A. Prevention of 30-day readmission after coronary artery bypass surgery. Home Healthc Now. 2017;35(6):326-34. doi:10.1097/ NHH.0000000000000555. 